\title{
Chile: Port congestion and efficient rationing in cargo transfer operations
}

\author{
Claudio A. Agostini and Eduardo H. Saavedra
}

ABSTRACT

No pricing system is likely to be able to do away with congestion in port cargo transfer operations at peak times, since port use is determined not so much by seasonal factors as, first and foremost, by the simultaneous arrival of vessels, which results in rationing. This article shows that rationing, to be efficient, needs to go by the value of the cargo transferred rather than following a first-come-first-served rule. It demonstrates that efficient rationing gives priority to containerized cargo, followed by break bulk cargo, with bulk cargo in last place. These findings are applied to cargo transfer at the San Antonio Terminal Internacional franchised port in Chile. claudio.agostini@uai.cl

Eduardo H. Saavedra is an associate professor at the Latin American Institute of Social Theory and Social Studies (ILAdes), Universidad Alberto Hurtado, Chile. saavedra@uahurtado.cl 


\section{I}

\section{Introduction}

The scale and long payback times of the investment that port cargo handling infrastructure requires mean that this infrastructure can be characterized as an essential input, one that presents severe capacity constraints at times of peak or high demand. Economic theory generally states that congestion should be eliminated or reduced efficiently by means of the pricing system. Unfortunately, this mechanism cannot be applied to ports in the way it can to electricity or drinking water consumption, since port infrastructure usage is driven not so much by seasonal factors as by the almost simultaneous arrival of too many ships. This implies that port use necessarily has to be rationed and thus that some ships have to wait.

The question of how best to ration is disputed, however. Although the first-come-first-served system is the best known, the economic literature has shown it to be highly inefficient, since the willingness to pay of shippers subjected to rationing varies greatly with the value of the cargo they are carrying (Strandenes and Wolfstetter, 2005; Button, 1979), besides which it increases port operating costs (Imai, Nagaiwa and Chan, 1997).

In conformity with the literature, this article shows theoretically and empirically that it is socially desirable to impose all rationing on the activities with the lowest value added. This value is measured in theory as the drop in the value of transported cargo when it is subjected to rationing. The result holds even when the model includes compensation for firms subjected to rationing or if there are effects on the cargo handling capacity of the port that depend on the type of service being rationed. The rationing criterion used in this paper is cargo value, with containerized cargo being distinguished from bulk cargo. The two cargo types present marked differences in value and in their cost to the port operator, chiefly in terms of operating times and port infrastructure use.
This study was motivated by a dispute submitted to the Competition Tribunal (TDLC) in Chile in 2007. A company called Terquim S.A. accused San Antonio Terminal Internacional (STI) and Empresa Portuaria San Antonio (EPSA) of abusing their dominant position by following a priority criterion for serving ships in the port rather than doing it on a first-come-first-served basis. Consistently with the findings of the present study, the TDLC rejected the argument put forward by Terquim and dismissed the charge in January 2010. Its ruling was upheld by the Supreme Court in September that same year, ${ }^{1}$ and with it the use of priority criteria rather than first-come-first-served for processing ships in the port.

Looking beyond this specific antitrust dispute, however, the economic arguments for rationing port infrastructure in a particular period of time are applicable to any port, as is the methodology proposed in this article.

The rest of this paper is organized as follows. Section II describes the institutional framework for public-private port ownership in Chile, the features of the port of San Antonio, the two companies operating there (STI and EPSA) and the main bulk cargo handled by STI (sulphuric acid). Section III reviews the literature on port rationing and explains why port infrastructure can be regarded as an essential facility. Section IV presents an economic model that shows why it is more efficient to ration by cargo value than on a first-come-first-served basis. Section V provides comparative estimates for the two methods at the port of San Antonio, using STI information for 2007. Lastly, section VI offers conclusions.

\footnotetext{
1 For further details, see Agostini and Saavedra (2008), TDLC ruling 96/2010 and the Supreme Court judgement with the reference Rol 1933/2010. See [online] www.tdlc.cl.
} 


\section{II}

\section{Description of the market and}

\section{institutional framework}

\section{Public-private port partnerships in Chile}

During the 1980s and 1990s, the Chilean Port Enterprise (EMPORCHI) operated the 10 State-owned ports under a multi-operator system. Under this system, the State enterprise administered the port infrastructure and a number of private-sector firms carried out loading and unloading of ships at the ports. One of the great drawbacks of this system was that it divided cargo up among a number of firms at the same port, seriously limiting incentives to invest in cargo handling equipment and preventing port infrastructure from being used efficiently.

As international trade grew strongly in Chile, port management began to turn into a bottleneck, and in the late 1990s the Government took the decision to modernize the State port sector. The key goals of the reform were to stimulate and dynamize investment in port infrastructure, technology and management. To this end it was proposed that the multi-operator system should be replaced by a single operator system in which a single firm took responsibility for operating and maintaining a port terminal. This would make it possible to promote competition both between ports and at the tendering stage when selecting the future single operator. A reform was accordingly proposed to break up EMPORCHI, involve private-sector firms in State port development via the concession mechanism and modernize labour practices at ports.

The reform approved in 1998 created 10 autonomous State port enterprises, each owning a single port, with the explicit objective of administering, operating, developing and preserving their respective ports and terminals. The law also gave each of these enterprises the mission of promoting competition between ports and within their own port and of involving the private sector to increase efficiency and investment. For this, the port enterprises may tender the concession of contracts for private-sector firms to operate and invest in each of the port terminals owned by them. Under the concession system, each State port enterprise continues to own the infrastructure and oversees the concession contract, being paid a minimum annual rent by the concession holder plus a percentage of its revenues.

In 1999, the concessions for Chile's three main port terminals, San Antonio, Valparaíso and San Vicente (Talcahuano), accounting between them for about $50 \%$ of all cargo handled by EMPORCHI, were put out to tender. Two criteria were followed in awarding the concessions: (i) a tariff index calculated from the dues for ship wharfage, cargo wharfage, container transfer and break bulk cargo transfer, and (ii) an annual fee or payment to the State.

This article will now focus on cargo activity at the port of San Antonio, the largest in Chile for total cargo handled and the second-largest for containerized cargo, according to figures for 2011 from the Infrastructure Services Unit of ECLAC.

\section{Public- and private-sector port enterprises at San Antonio}

The State firm EPSA has four berthing facilities with a total of nine berths and a total surface area of 495 hectares, 353 hectares of this being sea and 142 land. The basin has a surface area of 75 hectares and the four terminals are the Molo Sur (berths 1, 2 and 3), the Espigón (berths 4, 5, 6 and 7), the Terminal Norte (berth 8 specializing in dry bulk cargoes) and berth 9, specializing in wet bulk cargoes.

The tendering process for the port of San Antonio covered the Molo Sur and Terminal Norte concessions. The Molo Sur, with the largest-capacity berths, was awarded to San Antonio Terminal Internacional (STI), with a tariff index of US\$ 7.05 a ton, an upfront payment of US\$10 million, an annual fee that came to US\$ 11,050,606 in 2007 given the tonnage handled that year, and an additional payment of US\$121,252,062 split into six equal annual instalments in the first six years of the concession. The Terminal Norte was awarded to Puerto Panul and the other five berths are operated by EPSA. Thus, STI holds the concession to operate and administer the Molo Sur terminal, specializing in containers. For this purpose it had 769 metres of continuous wharf with 12 metres draught right 
along its docking area at the time of the concession, ${ }^{2}$ 31 hectares of dockside area ( 25 being used for storing containers and bulk cargoes), 6 gantry cranes, 9 forklifts, 41 tractor trucks for handling containers and cargo within the terminal, an area for container consolidation and deconsolidation, 6,000 square metres of roofed cargo storage, 2,000 connections for reefers, railway access to the dockside and container loading areas, and a weighbridge for weighing trucks with bulk or containerized cargo.

The concession contract with sTI stipulates loading and unloading speeds and waiting times that must be kept to, failing which the concession holder is fined. It also includes stipulations for a progressive improvement in the service provided by the concession holder over the life of the contract. This provides an incentive for the concession holder to invest as necessary to maintain and improve the standard of service without the need to stipulate specific investments or investment amounts. Basic tariffs are set in the concession contract; however, the concession holder can charge special tariffs for additional services provided at users' request. This encourages the concession holder to invest in accordance with developments both in the technical progress of

2 There are currently 380 metres with an authorized draught of 13.5 metres and 389 metres with an authorized draught of 11.34 metres. port operations and demand from its various types of customers, who require different levels of service.

Because container use has substantially reduced cargo handling costs, thereby increasing national and international short sea shipping (Clark, Dollar and Micco, 2004; Blonigen and Wilson, 2008), one of the goals of the tendering process was precisely that there should be investment in increased containerized cargo transfer capacity and efficiency. This trend can also be observed at the port of San Antonio, both in the evolution of the number of dockings at each terminal by vessel type (see figure 1) and in the total amount of cargo transferred by vessel type (see figure 2) and performance by type of cargo transferred (see figure 3 ).

The evolution of cargo in recent years, as reflected in figures 1,2 and 3, shows not only the tendency towards greater containerization but also the increase in port efficiency brought by containerization. Consequently, having docking facilities that specialize in containerized cargo yields efficiency gains over facilities that mix bulk and containerized cargoes. This is important, as trade volumes can fall off considerably at inefficient ports and the impact can be still greater in small and developing countries (Blonigen and Wilson, 2008).

Berths are a public good, and this implies nondiscriminatory public tariffs and an obligation to accept ships and handle cargo. Accordingly, all the landlord

FIGURE 1

STI: number of dockings by vessel type, 2001-2006

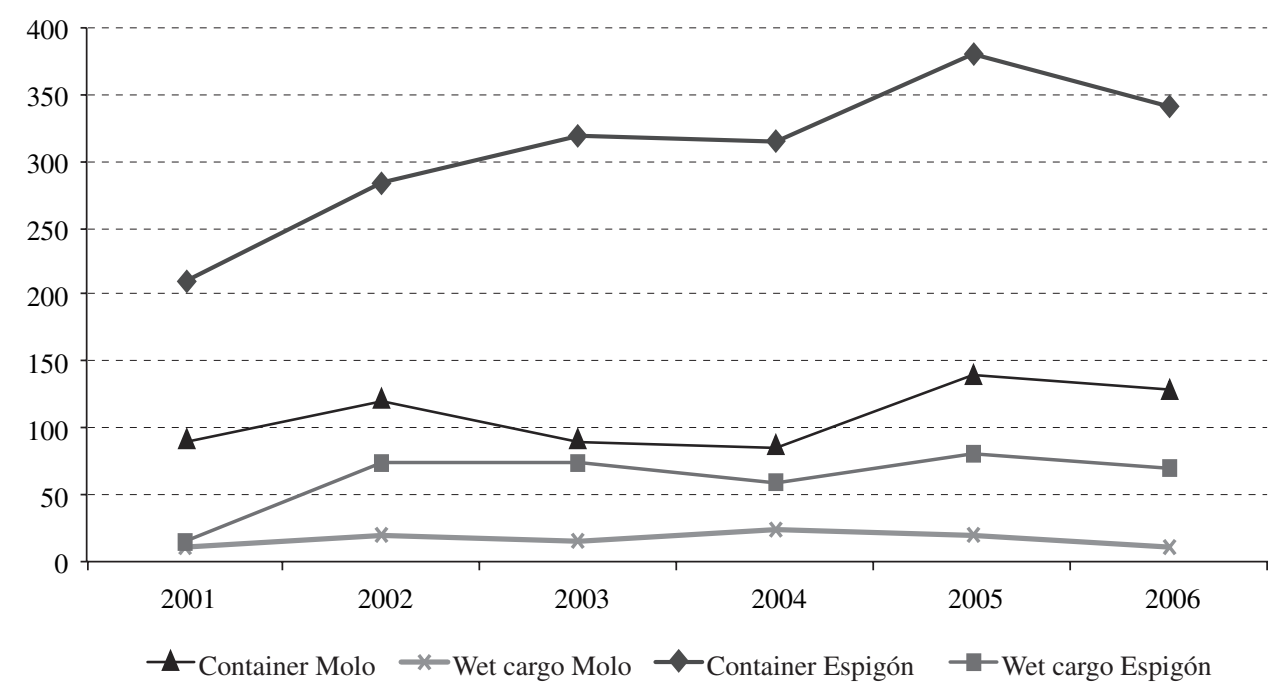

Source: prepared by the authors on the basis of information from San Antonio Terminal Internacional (sTI), Chile. 
FIGURE 2

STI: tonnage transferred by cargo type, 2000-2006

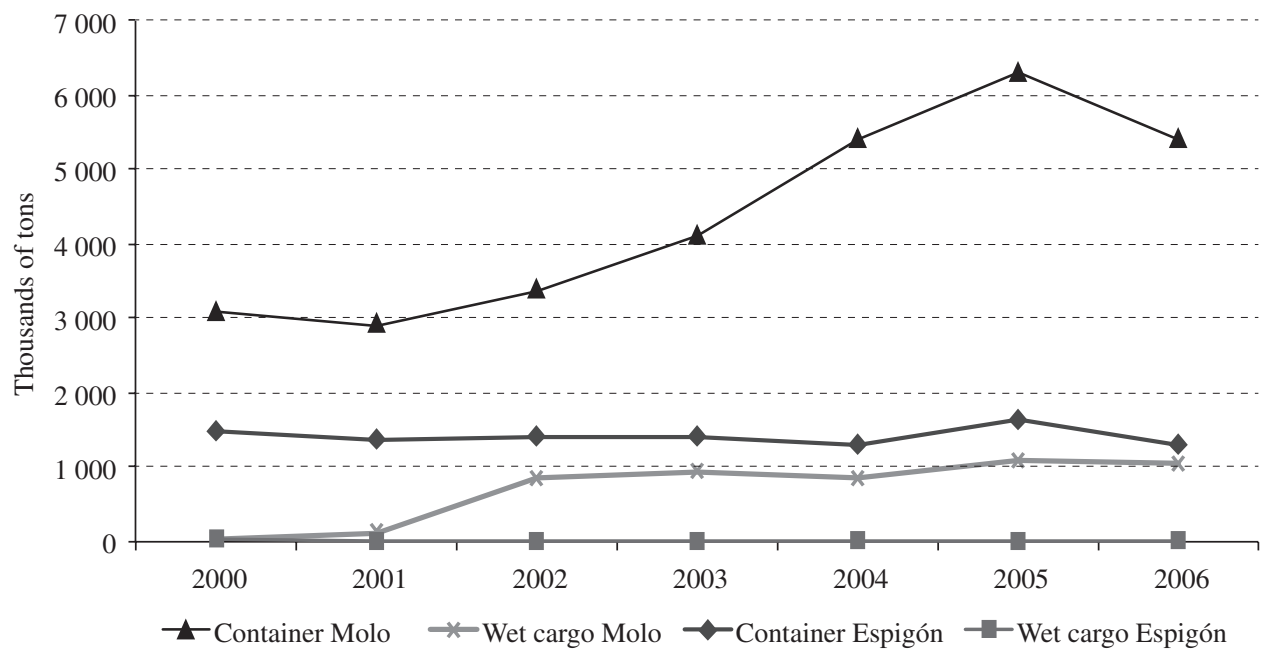

Source: prepared by the authors on the basis of information from San Antonio Terminal Internacional (STI), Chile.

FIGURE 3

STI: performance by type of cargo transferred, 2000-2006

(Tons/hour)

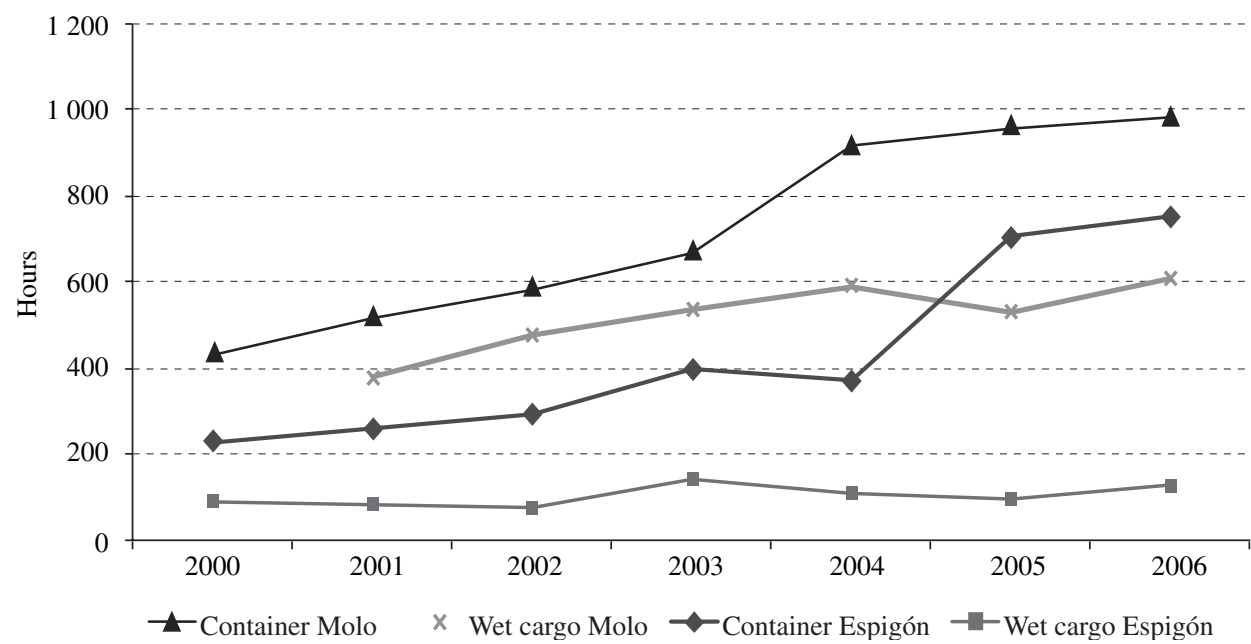

Source: prepared by the authors on the basis of information from San Antonio Terminal Internacional (STI), Chile.

ports have internal regulations on the use of docking facilities that are designed to ensure efficient usage of port infrastructure and freedom of choice for users. The service manual lays down docking priority rules and procedures, establishing that dockings must be scheduled on the basis of an objective technical priority rule. Table 1 shows the priorities established for the three berths operated by STI. These priorities reflect preferences for cargo types with faster transfer speeds and port services that operate vessels regularly. 
TABLE 1

Chile: STI berthing priorities

\begin{tabular}{|c|c|c|c|}
\hline & Berth 1 & Berth 2 & Berth 3 \\
\hline 1 & Scheduled container ships & Scheduled container ships & Container ships \\
\hline 2 & $\begin{array}{l}\text { Scheduled break bulk } \\
\text { cargo ships }\end{array}$ & $\begin{array}{l}\text { Scheduled ships loading } \\
\text { over } 10000 \text { tons of } \\
\text { homogeneous cargo }\end{array}$ & $\begin{array}{l}\text { Ships loading over } 10000 \text { tons } \\
\text { of homogeneous cargo }\end{array}$ \\
\hline 3 & Bulk cargo ships & $\begin{array}{l}\text { Scheduled break bulk } \\
\text { cargo ships }\end{array}$ & $\begin{array}{l}\text { Scheduled break bulk } \\
\text { cargo ships }\end{array}$ \\
\hline 4 & Other ships & Bulk cargo ships & Bulk cargo ships \\
\hline 5 & & Other ships & Other ships \\
\hline
\end{tabular}

Source: San Antonio Terminal Internacional (STI), Chile.

\section{The sulphuric acid storage contract and loading protocol}

Transportation of sulphuric acid from the El Teniente mine operated by the Chilean National Copper Corporation (CODELCO) to the port of San Antonio is carried out in three sequential stages: trucks, railway and, once in San Antonio, storage in tanks and loading. This last stage is carried out by Terquim, with $97 \%$ of all the cargo transferred by Terquim being sulphuric acid. The firm also has the concession to operate at the Molo Sur, i.e., at the terminals awarded to STI.

While sTi does not follow a berth reservation policy and thus does not promise to prioritize particular ships over others beyond what is stipulated in its service manual, the contract between STI and CODELCO makes STI responsible for any environmental problems caused by an overflow at the Terquim terminals due to berth unavailability. The aim of this contractual provision is to minimize the time ships carrying sulphuric acid for CODELCO have to wait out at sea, to which end it limits the time the concession holder can keep these ships waiting before they are unloaded, with the clock running from the time the vessel reaches the pilot station until docking manoeuvres begin. The fine prescribed in the contract as applicable in 2007 was US\$20,000 a day (calculated pro rata for shorter waiting times). In addition, the cost of taking the ship out to an anchorage has to be met by STI (tugs, time, etc.) if it decides to do this. CODELCO, in turn, pays a fixed tariff per ton of acid, this being US\$ 1.05 as of April 2008.

The contract specifies three levels of sulphuric acid in the tanks and maximum waiting times before STI has to service ships, depending on the volume accumulated. The volumes and maximum waiting times are: green level, less than 26,000 tons with a maximum wait of 48 hours; yellow level, between 26,000 and 33,000 tons with a maximum wait of 24 hours; and red level, over 33,000 tons with a maximum wait of 6 hours.

In principle, this contract is an efficient economic solution because it is consistent with the literature on port rationing, as shown in section III, and with the theoretical prediction of an economic model of efficient rationing developed in section IV. On the one hand, this rationing criterion gives CODELCO certain guarantees that the sulphuric acid tanks will not fill up completely but will always have the capacity to store acid produced by its smelter. On the other, there is an opportunity cost to STI when it uses a berth for a container vessel and has to pay to keep an acid ship waiting for longer than stipulated in the contract. The economic effect of this contract is precisely to create the right signals so that the use of a docking facility with limited capacity is rationed efficiently. 


\section{III}

\section{The economic literature on rationing}

The literature on rationing the use of a good, and port infrastructure in particular, will now be reviewed. The section will end with a brief discussion of essential inputs, given the special characteristics of the good subject to congestion in this case.

\section{Rationing and the economic rationale}

The need to ration the use of a good arises when it is costly to modify prices (waiting time in restaurants), when rationing signals quality (medical care or luxury goods) or when there are temporary increases in demand and consumers face switching costs. As a result, there are markets where excess demand leads not to price increases but to rationing for consumers. This happens in markets as diverse as restaurants, electronic components, semiconductors, personal computers, metals, titanium dioxide, polypropylene, petrochemicals, compact discs and children's toys (MacKinnon and Olewiler, 1980; Ghemawat, 1986; Basu, 1987; Carlton, 1991; Slade, 1991; Ungem-Sternberg, 1991; Haddock and McChesney, 1994; De Graba, 1995).

Going by this evidence in different markets, the economic literature has focused on trying to explain the existence of time rationing as an equilibrium situation, and also on determining the optimal rationing mechanisms when it is not possible or desirable to adjust by raising prices.

In one of the seminal articles of this literature, Barzel (1974) established the economic rationale behind first-come-first-served rationing, noting that the waiting time simply created an extra cost for consumers of a good. When a good is available in limited quantities, the time-price mix plays the same role as the monetary price when there is no restriction on quantity; nonetheless, there is a loss of efficiency relative to the unrationed equilibrium. In the event that there are no constraints on the availability of the good but there is price rigidity, the logic is equivalent to Barzel's and waiting time simply serves the purpose of reducing excess demand until it is in balance with the supply of the good (Alderman, 1987).

Even if there are no price rigidities, however, it can still be optimal for a firm to ration rather than raising prices. Bose (1996) shows that when there are users who differ in their willingness to pay and this characteristic is unknown to the supplier, waiting times become an effective mechanism for discriminating between them, insofar as demand and thus willingness to pay are greater among those who wait. As a result, there is an equilibrium with rationing whereby it is more profitable for the supplier to ration consumers than to charge higher prices to achieve market equilibrium.

Looking past the different theoretical explanations given in the literature to account for the existence of rationing as an equilibrium situation in a market, what is relevant in this case is to consider how optimal the different rationing mechanisms are. An early contribution was made by Greenberger (1966), who noted that the optimal system of priorities depended on the objective, as there is a conflict between minimizing the average waiting time and its variance. Thus, a rule giving priority to consumers who need to be served more quickly can be used to minimize the mean waiting time and the number of consumers waiting, but at the cost of increasing variance. Conversely, a first-come-first-served rule serves to control variance in waiting times.

Both rationing criteria assume that the cost of waiting is the same for all consumers. If it is not, there are more efficient options for setting priorities in accordance with how important or urgent the service is for different types of consumers. Thus, Pestalozzi (1964) and Likens (1976) show that a priority index is more efficient than a first-come-first-served system in airport operations. In particular, Pestalozzi's work shows that if the goal is to minimize the average cost of delay, the optimal approach is to introduce priorities by aircraft type, applying the rule that landings have priority over take-offs. It is important to stress that the first-come-first-served rule is never optimal in any of the cases simulated.

Greenberger (1966) considers different rules for computer time-sharing and establishes that the optimal method is to prioritize users by the waiting cost of each, attending first to those for whom the cost is highest. This is similar to the earlier finding of Cox and Smith (1961), who showed that when service delay costs were heterogeneous, the average cost of delay for consumers was minimized by working down the priority list, defined as the waiting cost per unit of time divided by the expected service requirement. 
Subsequently, Naor (1969) showed that the firstcome-first-served rule, when applied to a homogeneous population of consumers, led to a degree of congestion in excess of what was socially optimal, making it necessary to raise the price to a level that reduced congestion or charge an extra tariff for the same purpose. This finding was subsequently extended by Balachandran and Schaefer (1979) for a situation in which there were heterogeneous consumers.

The paper by Sherman and Visscher (1982) considers the optimal pricing strategy along with rationing mechanisms when demand for a service is stochastic. Their findings show that a rationing mechanism based on priority for consumers with a greater willingness to pay entails an optimal price that is the same for all consumers. Conversely, a rationing mechanism that prioritizes consumers who value the service less entails discriminatory optimal pricing whereby higher prices are charged to consumers who are more willing to pay.

These findings are relevant to the rationing of port infrastructure use, as they show that when it is not possible to charge different prices for different types of consumer and it is mandatory to charge a single nondiscriminatory price, the optimum is to ration excess demand in descending order of willingness to pay.

\section{Rationing in port infrastructure use}

The great majority of studies in the port rationing literature agree that the first-come-first-served mechanism is inefficient, unless all arriving ships and cargoes are identical. Strandeness and Wolfstetter (2005) state that the first-come-first-served criterion is highly inefficient, as it does not reflect ships' relative waiting costs. Likewise, Imai, Nagaiwa and Chan (1997) conclude that if the aim is to achieve high port productivity, first-come-firstserved should never be considered as an option for the optimal allocation of berths.

For reasons of efficiency, then, a port should discriminate by means of tolls (extra tariffs) or other mechanisms. Jansson and Ryden (1979) suggested using a two-part tariff, divided into a charge reflecting the opportunity cost of using the port facility and another charge per ton that would be differentiated on the basis of demand elasticity. Similarly, Button (1979) evaluates the design of an economic pricing system in which one criterion is that users of a port should pay the marginal social opportunity cost of the resources they use. The outcome is that ports should charge a two-part tariff, consisting of one charge for cargo, based on the marginal social opportunity cost, and a fixed charge for the right to use the port, based on frequency and the amount of time it is used for. Under this system, regular users of the port have priority over infrequent users, since the first-come-first-served system does not reflect each ship's effective demand for port services.

Following this line of argument, Ghosh (2002) shows that it is optimal to give priority to the ships that most value the service and suggests a system of sequential berth auctions for this purpose. Setting out from this idea, and applying the Vickrey-Clarke-Groves mechanism, Strandenes and Wolfstetter (2005) propose a system of berth auctions using a mechanism that ensures that the bids reveal the true value to each ship of docking at the place and time being auctioned.

Looking beyond theoretical considerations and the consensus in the literature regarding the inefficiency of the first-come-first-served system of berth allocation, in practice different prioritization systems have been increasingly employed at different ports all over the world. For example, Imai, Nishimura and Papadimitriou (2004) argue that allocating berths in a way that takes considerations of priority into account is very important for port operators working in a competitive environment, particularly in view of the greater flexibility it gives them in their decisions about infrastructure use.

Consequently, some ports establish ship size or cargo volume as a priority criterion. For example, port authorities in Japan, Singapore and Norway give priority in some ports to the ships with the largest volume of containers (Imai, Nagaiwa and Chan, 1997; Imai, Nishimura and Papadimitriou, 2004; Svendsen, 1967).

\section{Ports as an essential facility}

Conceptually, an essential facility or essential infrastructure can be understood as the basic input for supplying firms that participate in competitive segments (even if competition is imperfect) of an industry, where this basic input is provided under conditions of monopoly or market power. It is important to stress that market power deriving from ownership or control of the operation of assets deemed essential does not necessarily have to be monopolistic, as it is enough if the operator of these assets is able to set a completely unregulated limit price that yields rents beyond what their operation would normally provide.

The first thing that needs to be properly understood about the essential facility concept is that the industry has to have a vertical structure, i.e., the market serving consumers must necessarily require access to a basic input because alternative inputs do not exist or are 
economically unviable. ${ }^{3}$ In the case of a port, this essential facility interacts with different shipping companies offering containerized, bulk or break bulk cargo transport services. There are also indirect users of the port, such as producers and final consumers of the goods transported. Other actors likewise participate in the port cargo transportation activity, examples being the shipping authority and the pilot stations before or after a ship arrives at or leaves its berth, plus customs, customs agencies and the Agriculture and Livestock Service before or after a ship's arrival.

The second thing that has to be understood is that not every type of essential facility needs to be regulated. It is possible to find industries with low sunk costs and little market power in which there is competition for essential facilities, with two or more firms opting to build their own essential facility, sometimes even offering access (paid for but freely determined by the market) to their rivals in the market for the final customer. An example of this might be a liberalized health-care industry (Robinson and Casalino, 1996) or the telecommunications industry (Valetti and Cambini, 2005; Mancero and Saavedra, 2006). Alternatively, there are industries with larger sunk costs where two or more competitors share their essential facilities, sometimes as a market outcome upon the entry of a new competitor, possible examples being

3 Strictly speaking, the port industry does have imperfect substitutes for the essential facility, such as more distant ports in the same country or a State port at the same place. They are imperfect because the cost of access to them is greater (in money or waiting times). the liquid fuel industry (Balmaceda and Saavedra, 2007) and the air transport industry (Agostini, 2008 and 2012).

If the decision has been taken to regulate the tariffs and quality of the essential facility, then two points are worth analysing. First, when the auction process for the port privatization or concession is being designed, care needs to be taken with the ex post conditions governing the actual operation of the facilities (Engel, Fischer and Galetovic, 2004), with particular attention being paid to the conditions of ownership of the private-sector operators, the horizontal structure of the industry, tariff regulation and regulation of the quality of the service to be provided. Second, if the choice is made not to separate the industry vertically, the port operator may have commercial interests in the shipping market, enabling it to sabotage rivals by giving them a lowerquality service than it provides to its own ships (Mandy and Sappington, 2007). The Chilean regulations guard against these risks by laying down explicit rules for service priority, waiting times and quality standards that are overseen by the relevant port regulator.

In summary, the concession of port infrastructure operations is economically efficient if the tendering and regulation processes mimic a competitive market, providing the right signals to the operator with respect to pricing, service quality and most particularly investment. Consequently, the matter of whether the right port investments have been made is not in dispute, since congestion at given price levels is something that is bound to arise anyway at some point, and it is precisely then that an efficient way of handling rationing is needed.

\section{IV}

\section{An efficient port rationing model}

\section{The basic model}

Given the decision taken by the State prior to the port tendering process, particularly industry ownership and structure constraints and the setting of prices for the various services, the port operator will be faced with the need to ration use of the essential facility at times of high service demand. Simply put, whatever volume of investment may be needed, the optimal and actual situation is that there will be periods when the port infrastructure will have capacity available to cope with any type of cargo and, optimally, there will be other periods when it will be overwhelmed by excess demand.

It will now be shown that efficient rationing is achieved by assigning all port activity at periods of high demand to the container service, leaving the residual capacity for other services with less value added, such as bulk or break bulk cargo, which will be dealt with once the congestion is over. This is the right thing to do as long as there are no externalities affecting the population as a result of any spillages caused by excessive build-up of hazardous bulk cargoes in the port, an example being sulphuric acid at times when large volumes accumulate. 
This cargo handling allocation in favour of containers is generally more efficient for three reasons: greater profits in the form of surpluses for users of port services, greater profits for the port operator and greater port capacity available for services provided at times of high demand. ${ }^{4}$

Assuming that port activity is restricted to just two activities, namely container transfer $(C)$ and bulk cargo transfer $(B)$, only three periods are relevant: the first, in which there is no rationing because total demand for the two activities falls short of installed capacity $(K)$; the second, when the demand for container transfer increases to the point where total demand exceeds installed capacity $\left(D_{1}>K\right)$; and the third, when demand returns to normal and the demand subjected to rationing in the previous period is also dealt with. The prices for these services are regulated exogenously, and are thus equal to $p^{C}$ and $p^{B}$, and costs are respectively $c^{C}$ and $c^{B}$, where $p^{C}>p^{B}>$ $c^{B}>c^{C}$. This captures the fact that the margin earned by the concession operator on the container service is greater than the margin earned on the bulk cargo service. ${ }^{5}$

4 By greater port capacity is meant the speed with which ships transporting a given tonnage are loaded or unloaded. Thus, port capacity is higher when a ship is processed more quickly than another, given a constant cargo transfer tonnage.

5 This is once again subject to there being no risk involved in the build-up of bulk cargoes. If there is, $\mathrm{c}^{\mathrm{B}}$ will be greater, and may exceed the price charged for this activity.
Demand for the two services in the second and third periods is equal and is defined as $p^{C}=a-b \cdot Q^{C}$ and $p^{B}=a-b \cdot Q^{B}$, with bulk demand in the second period being the same and container demand in the second period growing to $p^{C}=a+\alpha-b \cdot Q^{C}$. Figure 4 summarizes the structure of the industry for the second and third periods, with the third period resembling the first.

Society's welfare is equal to the sum of the surpluses of service users plus the profits of the port firm. It is important to stress the relevance of incorporating the profits of the port firm into the social benefit because: (i) it uses them to pay for infrastructure investment and (ii) the right to operate the port has been awarded under a concession, which means that the expected rents from the business were captured by the State at the time the port operation was put out to tender with the annual fee and upfront payment required. Nonetheless, as will be shown later, the qualitative results do not change if only the surpluses of port service users are considered.

If we use the terms $\pi_{t}^{C}$ and $\pi_{t}^{B}$, respectively, for the net surpluses of container and bulk transfer customers $(t=1,2,3)$, social welfare is:

$$
W=W_{1}+W_{2}+W_{3}=\sum_{i=1}^{3}\left(U_{i}^{C}+U_{i}^{B}+\pi_{i}^{C}+\pi_{i}^{B}\right)
$$

FIGURE 4

Containerized and bulk cargo markets in periods of low and high demand

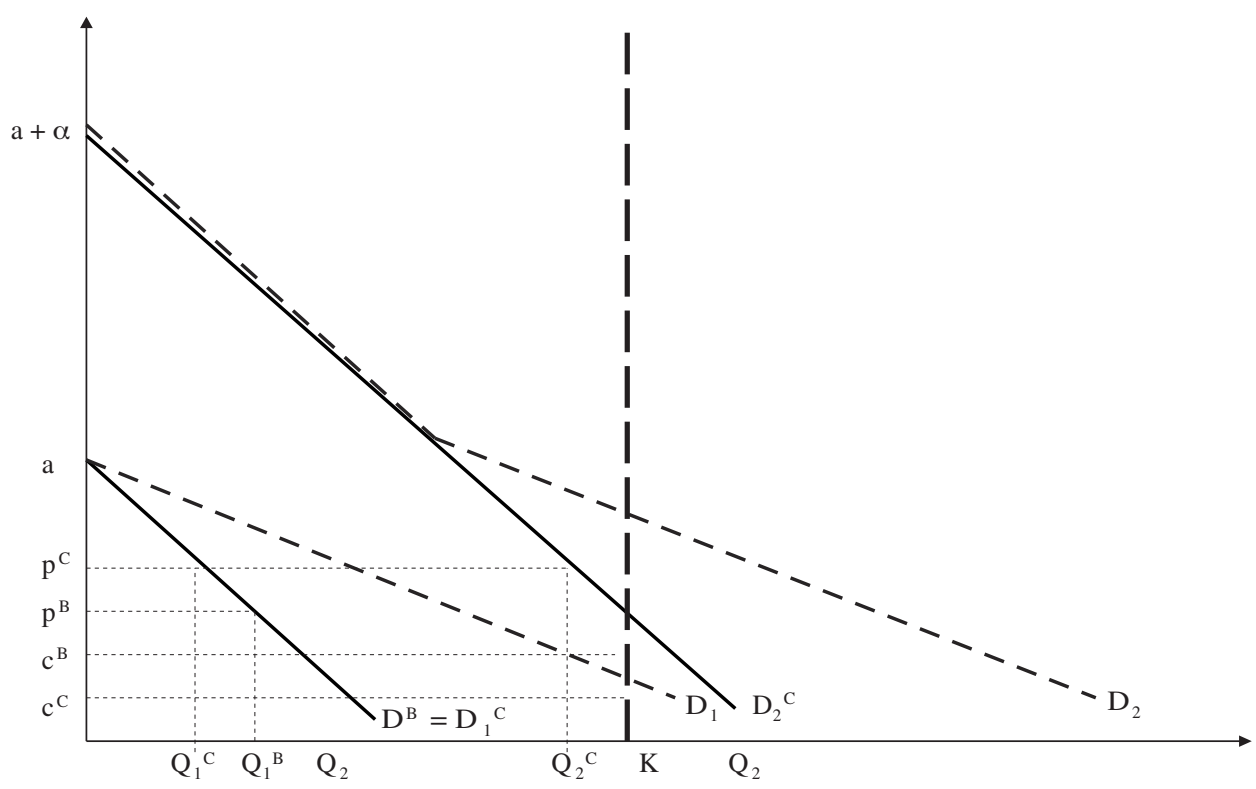

Source: prepared by the authors on the basis of information from San Antonio Terminal Internacional (STI), Chile. 
It should be noted that although demand is the same in all three periods, the surpluses of bulk users vary insofar as the service is rationed in the second period and the demand is wholly or partially met in the third period. To give a better understanding of these surpluses that social welfare is comprised of, figure 5 illustrates the four surpluses or profits for the second period. For simplicity, and solely for the purposes of figure 5 , it is assumed that there is no capacity constraint.

FIGURE 5

Social welfare in the second period without rationing

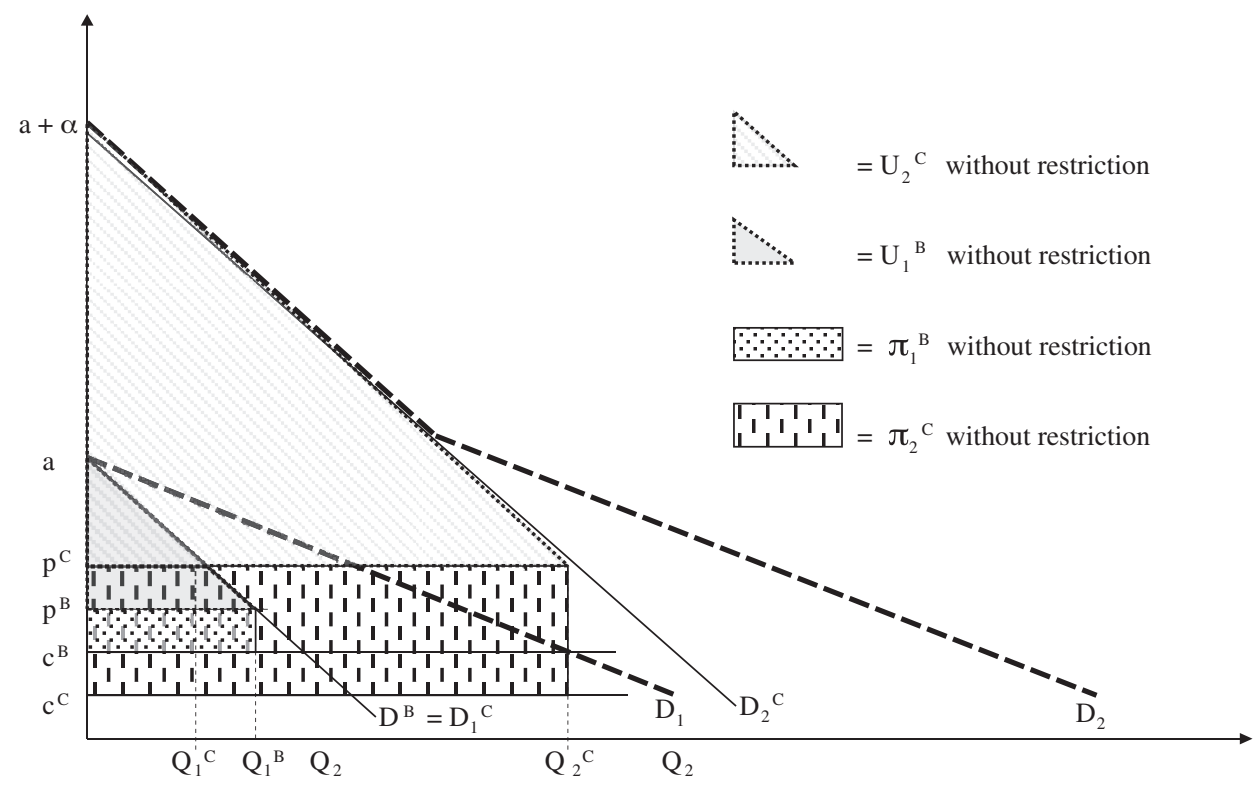

Source: prepared by the authors on the basis of information from San Antonio Terminal Internacional (STI), Chile.

To return to the general case, when there is rationing in the second period, it can be assumed that a proportion $\theta$ of the rationing is assigned to bulk activities, while ( $1-\theta)$ of this rationing is assigned to container activity. The cargo subjected to rationing is completely processed in the following period, but the user only receives a proportion of the surplus: $\delta^{C}$ and $\delta^{B}$. Given that in practice container activity is substantially more important to the country's economy and the customers of port services themselves, it is reasonable to assume that it is these who have most to lose by rationing, and this is captured in the model, with the assumption that $0<\delta^{C}$ and $\delta^{B}<1$. It should be explained that there is no flow discounting between periods, as rationing is assumed to be very short-lived, which means that $\delta^{C}$ and $\delta^{B}$ only represent the opportunity cost of the service not being provided when required. Lastly, it is assumed that the port firm forfeits $(1-f)$ of its profits by compensating a customer subjected to rationing, which covers fuel, wage and other costs, in addition to any compensation to third parties (like that payable to CODELCO in the case of sulphuric acid). This payment amount does not include any compensation for the shipping companies subjected to rationing; this would only constitute income transfers which would not affect the efficiency of resource allocation.

What will be reviewed first is the case where the installed port capacity required to process ships' cargoes is fixed and independent of the parameter $\theta$. Then consideration will be given to the case where this installed port services capacity in a given period increases as more rationing falls upon bulk activities, i.e.:

$$
\frac{\partial K}{\partial \theta}>0
$$

where $K \in[\underline{K}, \bar{K}]$. 


\section{Social welfare and rationing with fixed capacity}

The surpluses of users and of the port for the three periods are:

$$
\begin{aligned}
& W_{1}=U_{1}^{C}+U_{1}^{B}+\pi_{1}^{C}+\pi_{1}^{B} \\
& =\frac{1}{2}\left(a-p^{C}\right) Q_{1}^{C}+\frac{1}{2}\left(a-p^{B}\right) Q_{1}^{B}+\left(p^{C}-c^{C}\right) Q_{1}^{C} \\
& +\left(p^{B}-c^{B}\right) Q_{1}^{B}=-\frac{1}{2 b}\left[\left(a-p^{C}\right)^{2}+\left(a-p^{B}\right)^{2}\right] \\
& +\frac{1}{b}\left[\left(a-c^{C}\right)\left(a-p^{C}\right)+\left(a-c^{B}\right)\left(a-p^{B}\right)\right] \\
& W_{2}=U_{2}^{C}+U_{2}^{B}+\pi_{2}^{C}+\pi_{2}^{B} \\
& =\frac{1}{2}\left(a+\alpha-p^{C}\right) Q_{2}^{C}-(1-\theta) \frac{b}{2}\left(Q_{2}-K\right)^{2} \\
& +\frac{1}{2}\left(a-p^{B}\right) Q_{2}^{B}-\theta \frac{b}{2}\left(Q_{2}-K\right)^{2} \\
& +\left(p^{C}-c^{C}\right) Q_{2}^{C}-(1-\theta)\left(p^{C}-c^{C}\right)\left(Q_{2}-K\right) \\
& +\left(p^{B}-c^{B}\right) Q_{2}^{B}-\theta\left(p^{B}-c^{B}\right)\left(Q_{2}-K\right) \\
& =-\frac{1}{2 b}\left[\left(a+\alpha-p^{C}\right)^{2}+\left(a-p^{B}\right)^{2}\right] \\
& +\frac{1}{b}\left[\left(a+\alpha-c^{C}\right)\left(a-p^{C}\right)+\left(a-c^{B}\right)\left(a-p^{B}\right)\right] \\
& -\frac{1}{2 b}\left(2 a+\alpha-\left(p^{C}+p^{B}\right)-b K\right)^{2} \\
& -\frac{1}{b}\left[\left(p^{C}-c^{C}\right)-\theta\left[\left(p^{C}-c^{C}\right)-\left(p^{B}-c^{B}\right)\right]\right] \\
& \left(2 a+\alpha-\left(p^{C}+p^{B}\right)-b K\right) \\
& W_{3}=U_{3}^{C}+U_{3}^{B}+\pi_{3}^{C}+\pi_{3}^{B} \\
& =\frac{1}{2}\left(a-p^{C}\right) Q_{3}^{C}-\delta^{C}(1-\theta) \frac{b}{2}\left(Q_{2}-K\right)^{2} \\
& +\frac{1}{2}\left(a-p^{B}\right) Q_{3}^{B}+\delta^{B} \theta \frac{b}{2}\left(Q_{2}-K\right)^{2} \\
& +\left(p^{C}-c^{C}\right) Q_{3}^{C}+f(1-\theta)\left(p^{C}-c^{C}\right)\left(Q_{2}-K\right) \\
& +\left(p^{B}-c^{B}\right) Q_{3}^{B}+f \theta\left(p^{B}-c^{B}\right)\left(Q_{2}-K\right) \\
& =W_{1}+\frac{1}{2 b}\left(2 a+\alpha-\left(p^{C}+p^{B}\right)-b K\right)^{2} \\
& {\left[\delta^{C}+\theta\left(\delta^{B}-\delta^{C}\right)\right]} \\
& +\frac{f}{b}\left[\left(p^{C}-c^{C}\right)-\theta\left[\left(p^{C}-c^{C}\right)-\left(p^{B}-c^{B}\right)\right]\right] \\
& \left(2 a+\alpha-\left(p^{C}+p^{B}\right)-b K\right)
\end{aligned}
$$
with faster cargo transfer. is efficient to set $\theta=1$.

The first term of expression (6) shows the change in users' welfare as a consequence of assigning more rationing at the margins to the service with less value added, which is reflected in the fact that $\delta^{C}<\delta^{B}$. This is because users of container ships lose significantly more than users of bulk cargo ships when cargo loading or unloading is delayed. The second term is only significant when the port firm pays the costs entailed by the rationing and its profits are thereby reduced $(f<1)$, these costs being lower when efforts are focused on the activity

In view of this result, given that rationing is allowed because prices do not adjust to demand at a specific point in time when port services are provided, it is efficient to assign all rationing to bulk transfer activities; i.e., it 
Although this result applies fairly generally, it is not completely applicable when the population is confronted with negative externalities resulting from the excessive build-up of certain types of cargo, as can potentially occur with sulphuric acid in the case of San Antonio or with other toxic materials at other ports in the country. To capture a situation like this, the model can be modified for periods of sulphuric acid accumulation (something that is known about in advance and is not random), so that the (social) cost of postponing this cargo is rising and convex with the bulk cargo rationed, i.e., a function $S(\theta)$, so that $S^{\prime}(\theta)>0$ and $S^{\prime \prime}(\theta)>0$. On this assumption, expression (6) would become:

$$
\left.\frac{\partial W}{\partial \theta}\right|_{S(\theta)>0}=\left.\frac{\partial W}{\partial \theta}\right|_{S(\theta)=0}-S^{\prime}(\theta) \gtreqless 0
$$

If stored cargo is dangerous enough for the externality to generate considerable costs for society, then this effect will dominate so that, in a situation like the one described, it will be advisable to ration containers. The assumption must be that this will not usually be the case and equation (6) will therefore operate.

\section{Social welfare and rationing with endogenous capacity}

In the previous result concerning the efficiency generated by rationing the loading of bulk or break bulk cargo relative to containerized cargo, port capacity is assumed to be given (fixed and exogenous), which means it is relevant to consider whether this conclusion holds in the event of port capacity being endogenous. This is particularly important not just for the general robustness of a model in relation to its assumptions, but because in this case, as will be shown empirically further on, the evidence is that more time is required to transfer bulk cargo than to deal with a container ship of the same size.
Considering port capacity to be endogenous to the rationing decision implies, in terms of this model, that the capacity of the port increases as rationing is shifted from containers to bulk cargoes or, mathematically, $K=K(\theta)$, with $\frac{\partial K}{\partial \theta}>0$. It is assumed that $K(0)=$ $K$ and $K(1)=\bar{K}$ and ; however, even if all rationing were assigned to bulk activity, there would still be rationing, which means that $Q_{2}>\bar{K}$. Taking the results of the previous subsection, the effect of a rise of $\theta$ on social welfare is:

$$
\begin{gathered}
\frac{\partial W}{\partial \theta}=\frac{1}{2 b}\left(\delta^{B}-\delta^{C}\right)\left(2 a+\alpha-\left(p^{C}+p^{B}\right)-b K\right)^{2} \\
+\frac{1-f}{b}\left[\left(p^{C}-c^{C}\right)-\left(p^{B}-c^{B}\right)\right]\left(2 a+\alpha-\left(p^{C}+p^{B}\right)-b K\right) \\
+\left(2 a+\alpha-\left(p^{C}+p^{B}\right)-b K\right)\left(1-\left[\delta^{C}+\theta\left(\delta^{B}-\delta^{C}\right)\right]\right) \frac{\partial K}{\partial \theta} \\
+(1-f)\left[(1-\theta)\left(p^{C}-c^{C}\right)+\theta\left(p^{B}-c^{B}\right)\right] \frac{\partial K}{\partial \theta}>0
\end{gathered}
$$

where the last two terms of (8) are new, i.e., do not appear in expression (6), and capture the impact of lesser rationing insofar as this is assigned to bulk cargo transfer. Consequently, when this prioritization rule is adopted for port activity, both the direct effects of favouring containerized cargo and the indirect effects in the form of greater port capacity increase social welfare.

In the same way, if the social welfare repercussions of rationing bulk cargo, $S^{\prime}(\theta)$, were large enough, owing for example to the consequences of a higher probability of spillage for a hazardous cargo, then the effect would be the opposite of the one predicted in expression (8). It will be assumed that these cases are governed by protocols or contracts between the port and those generating the cargo, or regulated directly by environmental laws or regulations, so that rationing would be applied to containers in these circumstances. 


\section{$\mathrm{V}$}

\section{Applying priority criteria at the port of San Antonio in Chile}

The theoretical model presented earlier, consistently with the findings of the economic literature, shows that a rationing mechanism based on waiting instead of pricing is efficient and increases welfare in the case of a port with essential facility characteristics. The question is whether or not this model is consistent with the rationing applied in real-world port operations, and whether these predicted efficiencies actually exist. To consider how rationing by cargo type works in practice, we shall now analyse what happened with each of the wet cargo ships that arrived at the port of San Antonio and used sTI facilities during 2007. We then estimate the efficiency of rationing that favours containerized cargo (and break bulk cargo) as opposed to using the firstcome-first-served criterion to ration available capacity when this falls short of demand.

The form this rationing took in 2007 is first characterized. It is then shown that the port is more efficient at transferring containerized cargo than bulk cargo or, consistently with the section IV model, it is shown that $c^{C}<c^{B}$. Lastly, it is shown that it is better for society if containerized cargo is prioritized over bulk cargo, i.e., $p^{C}>p^{B}$. These port efficiency and welfare estimates are arrived at separately for sulphuric acid and other wet cargoes.

\section{Characterization of waiting times with efficient rationing}

Figure 6 shows the distribution of total waiting times for ships carrying sulphuric acid in 2007, counting from arrival at the pilot station until the first mooring line is attached at a berth. Of 41 ships carrying sulphuric acid, 15 had to wait longer than they would had they been serviced immediately and without interruptions. However, only 9 of these 15 cases can be ascribed to the priority rules (the black bars in figure 6), since according to STI the wait was due on four occasions to the berths being occupied by ships that had arrived first, just as a port would operate if it followed the first-come-firstserved rule (striped bars in figure 6), and in two cases CODELCO asked the ship to wait out at sea because there was not enough sulphuric acid to load (grey bars in figure 4). The effect of applying rationing by cargo

FIGURE 6

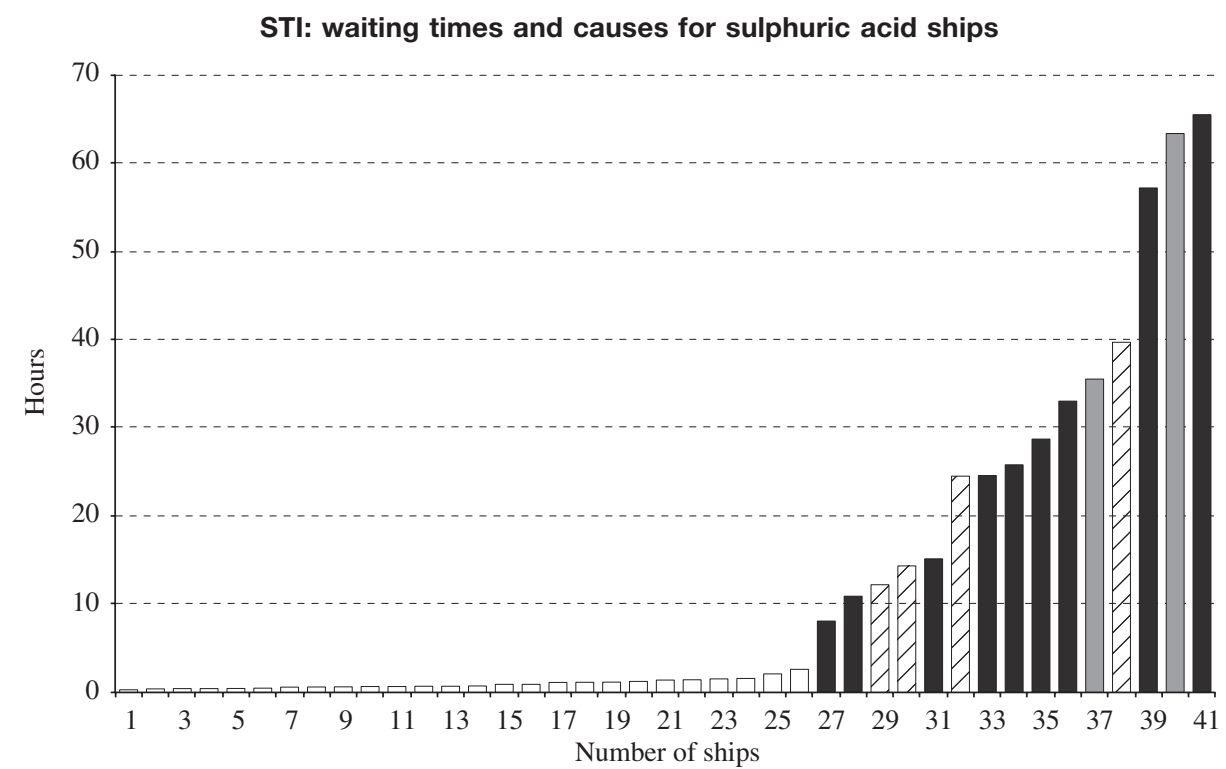

Source: prepared by the authors on the basis of information from San Antonio Terminal Internacional (sTI), Chile. 
type and sending bulk carriers out to sea was that this happened in $22 \%$ of sTI sulphuric acid loading operations in 2007 .

The situation with wet cargoes other than sulphuric acid was not much different. Figure 7 illustrates the distribution of total waiting times for these wet cargo ships in 2007. It can be seen that 22 such ships came into the port that year, of which just 5 , or $22.7 \%$, had to wait because of the sTI priority regulations (black bars in figure 7). In addition, two had to wait because the berths were in use by ships that had arrived earlier (striped bars in figure 7).

In summary, the conclusion from analysing information on waiting times at STI in 2007 is that $20 \%$ of wet cargo ships were subjected to a wait longer than they would have had under a first-come-first-served system.

FIGURE 7

STI: waiting times and causes for other wet cargo ships

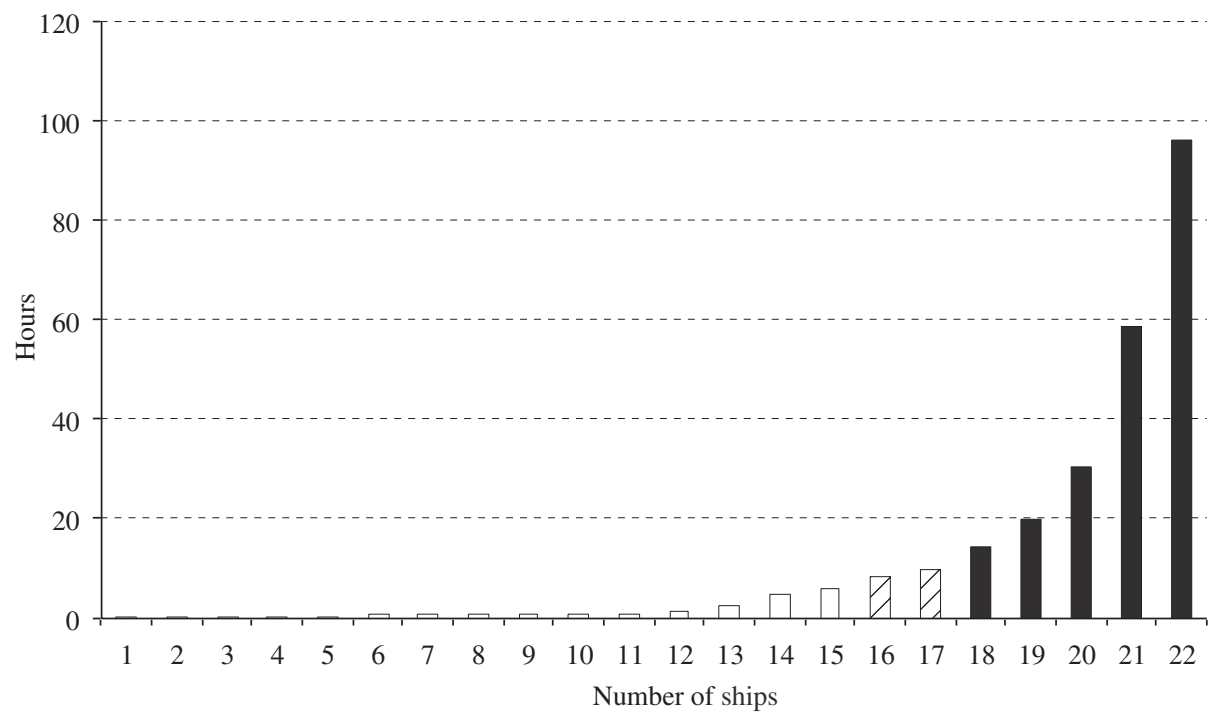

Source: prepared by the authors on the basis of information from San Antonio Terminal Internacional (STI), Chile.

\section{The opportunity cost of efficient rationing}

Whatever the percentage of times it happens or the percentage of ships affected, it is far more relevant to know the opportunity cost of the efficient rationing policy or, in other words, the estimated value of the containerized and break bulk cargo given priority over sulphuric acid and other wet cargoes. This information can be used to reach some kind of estimate of how much society gains by following the priority rule described instead of adopting a first-come-first-served rule. What is at issue is not social welfare, certainly, since it is not the demand for each product that is being estimated but the value of the cargo at market equilibrium prices. ${ }^{6}$

6 It is also important to bear in mind that the social opportunity cost of rationing sulphuric acid cargoes could be increased by the impact this measure would have on the mining operations that require it as a production input. It is assumed that since delays did not amount to so much as three days, at least in 2007 , this impact would not halt mining production (delays in 2007 averaged just under 30 hours).
- $\quad$ Ideal estimates

Bulk cargo $(B)$ has a gross value on a certain date $t$ of $v_{t}^{B}=p_{t}^{B} \cdot Q_{t}^{B}$. Ideally, this information could be obtained more precisely from the FOB value of the cargo transported. ${ }^{7}$ In this case, the gross value of a shipload of bulk cargo would simply be $v_{t}^{B}=F O B_{t}^{B}$. Similarly, containerized $(C)$ and break bulk cargo has a value for each shipload transported that is given by the same product of prices and quantities. Since cargoes on these ships are heterogeneous, the best way of estimating the gross value of the cargo transported in each ship $i$ at each moment of time $v_{j t}^{B}$ is simply to take its FOB value. Then, if a bulk cargo ship is subjected to rationing to make way for $\mathrm{J}$ ships carrying containers or break bulk cargoes or both, the gross value to society

7 The FOB value is the value of the merchandise put aboard the ship in the country of origin, excluding insurance and freight. 
of prioritizing the ships carrying this type of cargo is $\sum_{j=1}^{J} v_{j t}^{C}=\sum_{j=1}^{J} F O B_{j t}^{C}$.

Since the costs of processing any type of ship are essentially fixed, given that the greatest cost is the opportunity cost of the sunk infrastructure investment in wharves, cranes, manifolds, and so on, it is not enough to know how much space is occupied by each ship in the port, as the time (hrs) it takes to load or unload it also has to be established. Consequently, the right comparison is between the value of the cargo of a ship subjected to rationing and the value of the cargo of ships given priority over it:

$$
\frac{F O B_{t}^{B}}{h r s_{t}} \gtreqless \sum_{j=1}^{J} \frac{F O B_{j t}^{C}}{h r s_{j t}}\left(\frac{Q_{j t}^{C}}{\sum_{j=1}^{J} Q_{j t}^{C}}\right)
$$

In other words, each mean operation is weighted by the relative cargo transfer tonnages for the ship concerned.

Nonetheless, it is of the greatest interest to learn how large this difference was in a particular year, and for this it is enough to calculate the weighted average number of tons per hour for the whole of a given year:

$$
\begin{gathered}
\sum_{t=1}^{T} \frac{F O B_{t}^{B}}{h r s_{t}}\left(\frac{Q_{t}^{B}}{\sum_{t=1}^{T} Q_{t}^{B}}\right) \\
\left.\gtreqless \sum_{t=1}^{T}\left[\sum_{j=1}^{J} \frac{F O B_{j t}^{C}}{h r s_{j t}} \mid \frac{Q_{j t}^{C}}{\sum_{j=1}^{J} Q_{j t}^{C}}\right)\right]\left(\frac{\sum_{j=1}^{J} Q_{j t}^{C}}{\sum_{t=1}^{T}\left[\sum_{j=1}^{J} Q_{j t}^{C}\right]}\right)(10)
\end{gathered}
$$

In this case, $T$ refers to all bulk cargo ships subjected to rationing in a particular year where, as seen in the formula, mean transfers need to be weighted for each case.

\section{- Prioritization and efficiency: sulphuric acid}

Unfortunately, there is no publicly available information on FOB values for the loading and unloading operations carried out, which would allow an exact calculation to be made, so market or aggregate variables are used as a proxy for the true values; i.e., the cargo valued at market prices: $p_{t}^{a s} \cdot Q_{t}^{a s}$. For this purpose, information is available on the tonnage of each sulphuric acid ship subjected to rationing in $2007\left(Q_{t}^{a s}\right)$, and the average price paid for sulphuric acid by Chilean importers is used, the latest CIF value available as of 2008 being the average price for 2006: $p_{t}^{a s}=\mathrm{US} \$ 57.1$ a ton (COCHILCO, 2007). The rest of the relevant information for shipments of sulphuric acid in 2007 was supplied by STI and the relevant variables for this calculation are presented in table 2 .

The data show that it took an average of just under 30 hours to begin cargo transfer operations on ships subjected to rationing from the time they reached the port. This was 2.5 times the average time taken to start loading sulphuric acid on to the 41 ships that came to the port to take on this cargo in 2007, which was 11.76 hours. The rate at which sulphuric acid was loaded on to each ship subjected to rationing at STI that year was 573.5 tons an hour (average weighted by the amount loaded on to each vessel). To sum up, the average value of the sulphuric acid loaded on to these vessels subjected to rationing by the port in 2007 was US\$ 32,748 per ton/ hour of loading.

Regarding the ships given priority over those subjected to rationing, since the FOB value of each shipment is unknown, as are tonnages and prices, the implicit average price of Chilean exports and imports has been used, going by information from the Central Bank of Chile (FOB value of imports and exports in 2006) and the Maritime and Port Chamber of Chile (total amounts imported and exported that year). Going by these data, the average price estimated for 2006 is $p^{c o}=\mathrm{US} \$ 1,251$ a ton. ${ }^{8}$

Table 3 provides general information on the number of ships prioritized, tons transferred and the amount of time spent using the port for this, while the last two columns show the calculations for tons per hour and the value of these transfers, in accordance with expression (10).

The main conclusions from the data analysis regarding port efficiency are as follows:

(i) When the efficiency of the port at loading acid is compared with its efficiency at loading prioritized cargo, particularly containerized cargo, the findings are consistent with those predicted by the theoretical model inasmuch as the port is more efficient at transferring containerized and break bulk cargo than at loading sulphuric acid. The amount loaded on to prioritized ships for each hour of port infrastructure use averaged 773.35 tons (weighted) in 2007, while the equivalent average hourly transfer for sulphuric acid ships was 573.62 tons. It can be concluded that the port is more efficient at transferring containerized and break bulk cargo tonnage than at loading acid,

8 This price represents a lower bound to the actual average price for that year, since this proxy variable incorporates the weighted price of bulk cargo, which is lower than that of containerized and break bulk cargo. 
TABLE 2

STI: sulphuric acid ships subjected to rationing in 2007

\begin{tabular}{|c|c|c|c|c|c|}
\hline Arrival & Hours' wait & $\begin{array}{l}\text { Hours' loading } \\
\qquad h r s_{t}\end{array}$ & $\begin{array}{c}\text { Tonnage } \\
Q_{t}^{a s}\end{array}$ & Tons/hour ${ }^{\mathrm{a}}$ & $\begin{array}{c}\text { Value } \\
{\text { (per ton/hour })^{\mathrm{b}}}^{\mathrm{b}} \\
(\text { dollars })\end{array}$ \\
\hline 2 January & 57.15 & 44.15 & 25020 & 566.70 & 32359 \\
\hline 14 January & 28.70 & 48.05 & 25023 & 520.77 & 29736 \\
\hline 19 February & 25.78 & 20.73 & 11766 & 567.49 & 32404 \\
\hline 10 March & 65.45 & 47.50 & 26018 & 547.75 & 31276 \\
\hline 21 March & 15.13 & 44.75 & 26025 & 581.56 & 33207 \\
\hline 4 May & 33.00 & 39.60 & 26018 & 657.02 & 37516 \\
\hline 16 August & 8.08 & 22.95 & 11925 & 520.36 & 29713 \\
\hline 12 October & 24.50 & 43.55 & 26019 & 597.45 & 34114 \\
\hline 17 December & 10.90 & 26.63 & 15030 & 564.33 & 32223 \\
\hline Average & 29.86 & 37.54 & 21427 & 573.52 & 32748 \\
\hline
\end{tabular}

Source: prepared by the authors on the basis of information from San Antonio Terminal Internacional (sTI), Chile.

a The average transfer rate for ships subjected to rationing is weighted by the load of each (a simple average gives an average loading rate of 569.27 tons/hour).

b The load-weighted average of the final value for cargo subjected to rationing is equivalent to the expression on the left-hand side of equation (10), while the simple average would give a value of US\$32,505 per ton/hour.

TABLE 3

STI: ships prioritized over sulphuric acid ships in 2007

\begin{tabular}{|c|c|c|c|c|c|}
\hline Arrival & $\begin{array}{c}\text { Number of ships } \\
J\end{array}$ & $\begin{array}{l}\text { Hours' loading } \\
\qquad \sum_{j=1}^{J} h r s_{j t}\end{array}$ & $\begin{array}{c}\text { Tonnage } \\
\sum_{j=1}^{J} Q_{j t}^{c o}\end{array}$ & $\begin{array}{l}\text { Tons/hour } \\
\text { (weighted) }{ }^{\mathrm{a}}\end{array}$ & $\begin{array}{c}\text { Value } \\
{\text { (per ton/hour })^{\mathrm{b}}}^{\mathrm{b}}(\text { dollars })\end{array}$ \\
\hline 2 January & 3 & 41.98 & 20131 & 568.96 & 711732 \\
\hline 14 January & 3 & 75.42 & 41515 & 684.96 & 856832 \\
\hline 19 February & 2 & 33.47 & 28559 & 875.24 & 1094857 \\
\hline 10 March & 6 & 96.00 & 84606 & 956.45 & 1196443 \\
\hline 21 March & 2 & 53.42 & 24086 & 534.39 & 668481 \\
\hline 4 May & 2 & 43.95 & 41964 & 1063.72 & 1330628 \\
\hline 16 August & 2 & 44.38 & 28664 & 824.46 & 1031333 \\
\hline 12 October & 3 & 179.92 & 76249 & 556.84 & 696569 \\
\hline 17 December & 1 & 20.92 & 3234 & 154.61 & 193410 \\
\hline Average & 2.67 & 65.49 & 38779 & 773.35 & 967409 \\
\hline
\end{tabular}

Source: prepared by the authors on the basis of information from San Antonio Terminal Internacional (STI), Chile.

a The cargo prioritized for each ship subjected to rationing is weighted in accordance with equation $(10)$ as $\sum_{j=1}^{J} \frac{Q_{j t}^{c o}}{h r s_{j t}}\left(\frac{Q_{j t}^{c o}}{\sum_{j=1}^{J} Q_{j t}^{c o}}\right)$. The final average transfer for prioritized ships is weighted in turn by the transfer calculated earlier (a simple average gives an average loading rate of 691.07 tons/hour).

b The load-weighted average of the final value of the prioritized cargo is equivalent to the expression on the right-hand side of equation (10), while the simple average would give a value of US\$ 864,476 per ton/hour.

since it did the latter only $74.16 \%$ as effectively as the prioritized activity (or, to put it another way, the port is $34.84 \%$ more efficient on average at loading cargo on to prioritized vessels).

(ii) Looking at the respective efficiency of the two activities from the point of view of how society values their use, which is done by making some reasonable assumptions about the prices of the goods transported, the data reveal that containerized and break bulk cargo loading activities are 29.5 times as valuable as sulphuric acid loading activities. The value of the containerized and break bulk cargo prioritized by STI in 2007 averaged US\$ 967,409 an hour, while the value of the sulphuric acid cargo subjected to rationing by STI in 2007 averaged US\$ 32,748 an hour. Given the 
different orders of magnitude involved, then, there can be no doubt at all that it is socially preferable for port infrastructure use to give priority to containerized cargo.

- Prioritization and efficiency: other wet cargoes

The great heterogeneity of the other wet cargoes transferred means that the average price for these products in 2007 cannot be determined. It is possible, however, to show that in terms of efficiency in tons per hour of port infrastructure usage, a rule giving priority to containerized and break bulk cargo over wet cargoes is the right one. According to the relevant information on transfers of other wet cargoes for 2007 provided by STI and shown in table 4 , ships subjected to rationing had to wait an average of almost 44 hours, which was 3.8 times the average wait for a ship of these characteristics, whether subjected to rationing or not, at that port in 2007. The same table shows that the average cargo transfer speed for ships subjected to rationing was 135.4 tons per hour (average weighted by the amount loaded on each ship).

As for the ships given priority, table 5 shows that the prioritization rule set by STI was efficient. The cargo prioritized over other wet cargoes was loaded at an average rate of 821.33 tons per hour, which means that the port was $500 \%$ as efficient at moving containerized and break bulk cargo tonnage than at transferring other wet cargoes.

TABLE 4

STI: other wet cargo ships subjected to rationing in 2007

\begin{tabular}{|c|c|c|c|c|}
\hline Arrival & Hours' wait & $\begin{array}{c}\text { Hours' loading } \\
\qquad h r s_{t}\end{array}$ & $\begin{array}{c}\text { Tonnage } \\
Q_{t}^{\text {other }}\end{array}$ & Tons/hour ${ }^{a}$ \\
\hline 10 March & 58.75 & 8.72 & 786 & 90.17 \\
\hline 10 March & 96.25 & 17.25 & 1420 & 82.32 \\
\hline 30 June & 19.97 & 16.75 & 3122 & 186.39 \\
\hline 25 November & 14.42 & 11.00 & 948 & 86.18 \\
\hline 28 December & 30.50 & 12.25 & 1649 & 134.61 \\
\hline Average & 43.98 & 13.19 & 1585 & 135.44 \\
\hline
\end{tabular}

Source: prepared by the authors on the basis of information from San Antonio Terminal Internacional (sTI), Chile.

a The average transfer for ships subjected to rationing is weighted by the cargo of each (a simple average would give an average loading rate of 115.93 tons/hour).

TABLE 5

STI: other wet cargo ships prioritized in 2007

\begin{tabular}{|c|c|c|c|c|c|}
\hline Arrival & $\begin{array}{c}\text { Number of ships } \\
J\end{array}$ & $\begin{array}{l}\text { Hours' loading } \\
\sum_{j=1}^{J} h r s_{j t}\end{array}$ & $\begin{array}{l}\text { Tonnage } \\
\sum_{j=1}^{J} Q_{j t}^{c o}\end{array}$ & $\begin{array}{l}\text { Tons/hour }{ }^{\mathrm{a}} \\
\text { (weighted) }\end{array}$ & $\begin{array}{c}\text { Value }^{\mathrm{b}} \\
\text { (per ton/hour) } \\
(\text { dollars })\end{array}$ \\
\hline $10 \mathrm{March}$ & 2 & 19.08 & 13821 & 733.93 & 918086 \\
\hline 10 March & 5 & 71.42 & 57368 & 893.76 & 1118027 \\
\hline 30 June & 1 & 17.28 & 17257 & 998.46 & 1249002 \\
\hline 25 November & 1 & 14.70 & 2931 & 199.42 & 249459 \\
\hline 28 December & 1 & 30.60 & 18043 & 589.64 & 737596 \\
\hline Average & 2.67 & 30.62 & 21884 & 821.33 & 1027428 \\
\hline
\end{tabular}

Source: prepared by the authors on the basis of information from San Antonio Terminal Internacional (STI), Chile.

a The cargo prioritized for each ship subjected to rationing is weighted in accordance with equation (10) as $\sum_{j=1}^{J} \frac{Q_{j t}^{c o}}{h r s_{j t}}\left(\frac{Q_{j t}^{c o}}{\sum_{j=1}^{J} Q_{j t}^{c o}}\right)$. The final average transfer rate for prioritized ships is weighted in turn by the transfer rate calculated earlier (a simple average gives an average loading rate of 683.04 tons/hour).

b The load-weighted average of the total value of the prioritized cargo is equivalent to the expression on the right-hand side of equation (10), while the simple average would give a value of US\$ 854,434 dollars per ton/hour. 


\section{VI}

\section{Conclusions}

The economic literature analysing port congestion has consistently established that the first-come-first-served rule is inefficient in all cases except when all arrivals are identical. From a resource allocation standpoint, it is efficient to use discrimination mechanisms that can ration a scarce resource in an optimal way. In the application presented in this paper, it can be seen that at the landlord port of San Antonio in Chile, as in many other ports around the world, sTI follows a priority rule that allows berths to be employed efficiently, with containerized and break bulk cargo being prioritized over bulk cargo.

This paper employs a simple theoretical model which captures the relevant stylized facts for port infrastructure usage. This model allows conclusions to be drawn about the benefits of applying a priority rule in port operations instead of using the first-come-first-served rule. Its results show that, given the inflexibility of the pricing system in port concessions, there needs to be a criterion for rationing efficiently. What has been determined is that it is socially desirable, both for firms using the port and for the concession firm, for all rationing to fall upon the activities with the lowest value added. This lower value added has been conceptually measured by the fall in the value of the cargo being shipped when rationing is applied. This finding still holds if compensation for firms subjected to rationing is incorporated, or if it is assumed that port transfer capacity is affected depending on the type of service being rationed.

The empirical evidence for the berths operated under concession by STI is consistent with the theoretical results. The estimates for the efficiency of STI at transferring sulphuric acid and other wet cargoes, as compared to containers and break bulk cargo, indicate that the port is clearly more efficient at moving containerized and break bulk cargo tonnage per hour of port capacity usage. The estimates in this paper reveal that efficiency is $34.84 \%$ higher for container and break bulk cargo operations than for the sulphuric acid loading operations they displace in accordance with the port's priorities manual.

Furthermore, efficiency as measured by performance in the use of port facilities is $500 \%$ as great when the comparison is with ships loading other wet cargoes, displaced in accordance with the same priorities manual. Much the same conclusion is reached when the value of the shipped cargo is measured, with sulphuric acid being displaced by cargo worth 26.6 times as much.

It can be inferred from these results that rationing by shipped cargo value is perfectly consistent with economic efficiency, measured as the optimal use of port infrastructure. Furthermore, it is clear that the impact on ships carrying wet cargoes is minor, as just $22 \%$ had longer waits than they would have had under the inefficient first-come-first-served system. 
Agostini, C. (2012), "El mercado de transporte aéreo: Lecciones de política de una revisión de la literatura", Journal of Transport Literature, vol. 6, No. 3, São José dos Campos, Brazilian Transport Planning Society.

(2008), "La organización industrial del transporte aéreo en Chile", Revista de Análisis Económico, vol. 23, No. 1, ILADES/ Georgetown University.

Agostini, C. and E. Saavedra (2008), "Racionamiento eficiente en una facilidad esencial: El caso del Puerto de San Antonio" [online] http://www.tdlc.cl/DocumentosMultiples/Informe_Claudio_ Agostini_y_Eduardo\%20Saavedra_C_136_07.pdf.

Alderman, H. (1987), "Allocation of goods through non-price mechanisms: evidence on distribution by willingness to wait", Journal of Development Economics, vol. 25, No. 1, Amsterdam, Elsevier.

Balachandran, K. and E. Schaefer (1979), "Class dominance characteristics at a service facility", Econometrica, vol. 47, No. 2, New York, The Econometric Society.

Balmaceda, F. and E. Saavedra (2007), "Vertical integration and shared facilities in unregulated industries", Journal of Industrial Economics (Notes \& Comments), vol. 55, No. 4, Wiley, December.

Barzel, Y. (1974), "A theory of rationing by waiting", Journal of Law and Economics, vol. 17, No. 1, Chicago, The University of Chicago Press.

Basu, K. (1987), "Monopoly, quality uncertainty and 'status' goods", International Journal of Industrial Organization, vol. 5, No. 4, Amsterdam, Elsevier.

Blonigen, B. and W. Wilson (2008), "Port efficiency and trade flows", Review of International Economics, vol. 16, No. 1, Wiley Blackwell.

Bose, P. (1996), "Adverse selection, waiting lists and restaurant rationing", International Journal of Industrial Organization, vol. 15, No. 3, Amsterdam, Elsevier.

Button, K.J. (1979), "The economics of port pricing", Journal of Maritime Policy and Management, vol. 6, No. 3, Taylor \& Francis.

Carlton, D. (1991), "The theory of allocation and its implications for marketing and industrial structure: why rationing is efficient", Journal of Law and Economics, vol. 34, No. 2, Chicago, The University of Chicago Press.

Clark, X., D. Dollar and A. Micco (2004), "Port efficiency, maritime transport costs, and bilateral trade", Journal of Development Economics, vol. 75, No. 2, Amsterdam, Elsevier.

COCHILCO (Chilean Copper Commission) (2007), "El mercado del ácido sulfúrico en Chile proyectado al año 2015" [online] http:// www.cochilco.cl/anm/articlefiles/614-INFORMEASULF2006 VersionFINAL.pdf.

Cox, D. and W. Smith (1961), Queues, New York, John Wiley.

De Graba, P. (1995), "Buying frenzies and seller-induced excess demand", The RAND Journal of Economics, vol. 26, No. 2, Wiley.

Engel, E., R. Fischer and A. Galetovic (2004), "How to auction a bottleneck monopoly when underhand vertical agreements are possible", Journal of Industrial Economics, vol. 52, No. 3 , Blackwell Publishing.

Ghemawat, P. (1986), "Sustainable advantage", Harvard Business Review, Boston, Harvard Business Publishing, September.
Ghosh, M. (2002), "Bidding for a berth: an action based queue management mechanism for ports", Singapore Maritime \& Port Journal, Singapore, Maritime \& Port Authority of Singapore.

Greenberger, M. (1966), "The priority problem and computer time sharing", Management Science, vol. 12, No. 11, Institute for Operations Research and the Management Sciences.

Haddock, D. and F. McChesney (1994), "Why do firms contrive shortages? The economics of intentional mispricing", Economic Inquiry, vol. 32, No. 4, Wiley.

Imai, A., K. Nagaiwa and W. Chan (1997), "Efficient planning of berth allocation for container terminals in Asia", Journal of Advanced Transportation, vol. 31, No. 1, Wiley.

Imai, A., E. Nishimura and S. Papadimitriou (2004), "Berth allocation with service priority", Transportation Research Part B: Methodological, vol. 37, No. 5, Amsterdam, Elsevier.

Jansson, J. e I. Ryden (1979), Swedish Seaports: Economics and Policy, Stockholm, Stockholm School of Economics, The Economic Research Institute

Likens, J. (1976), "The welfare cost of nonoptimal airport utilization", Journal of Public Economics, vol. 5, No. 1-2, Amsterdam, Elsevier.

MacKinnon, J. and N. Olewiler (1980), "Disequilibrium estimation of the demand for copper", Bell Journal of Economics, vol. 11, No. 1, Santa Monica, RAND Corporation.

Mancero, X. and E. Saavedra (2006), "Un modelo de entrada y competencia en telecomunicaciones", Revista de Análisis Económico, vol. 21, No. 1, ILADES/Georgetown University.

Mandy, D. and D. Sappington (2007), "Incentives for sabotage in vertically-related industries", Journal of Regulatory Economics, vol. 31, No. 3, Springer.

Naor, P. (1969), "The regulation of queue size by levying tolls", Econometrica, vol. 37, No. 1, New York, The Econometric Society.

Pestalozzi, G. (1964), "Priority rules for runway", Operations Research, vol. 12, No. 6, Institute for Operations Research and the Management Sciences.

Robinson, J. and L. Casalino (1996), "Vertical integration and organizational networks in healthcare", Health Affairs, vol. 15, No. 1, Bethesda, Project HOPE — The People-to-People Health Foundation, Inc.

Sherman, R. and M. Visscher (1982), "Non-price rationing and monopoly price structures when demand is stochastic", The Bell Journal of Economics, vol. 13, No. 1, Santa Monica, RAND Corporation.

Slade, M. (1991), "Strategic pricing with customer rationing: the case of primary metals", Canadian Journal of Economics, vol. 24, No. 1, Wiley.

Strandenes, P. and E. Wolfstetter (2005), "Efficient (re-)scheduling: an auction approach", Economics Letters, vol. 89, No. 2, Amsterdam, Elsevier.

Svendsen, A.S. (1967), Does the Traditional Set-up of Port Charges Favour Old and Unmodern Ships?", Bergen, Institute of Shipping Research.

Ungem-Sternberg, T. (1991), "Rationing in restaurants", International Journal of Industrial Organization, vol. 9, No. 2, Amsterdam, Elsevier.

Valetti, T. and C. Cambini (2005), "Investments and network competition", RAND Journal of Economics, vol. 36, No. 2, Santa Monica, RAND Corporation. 